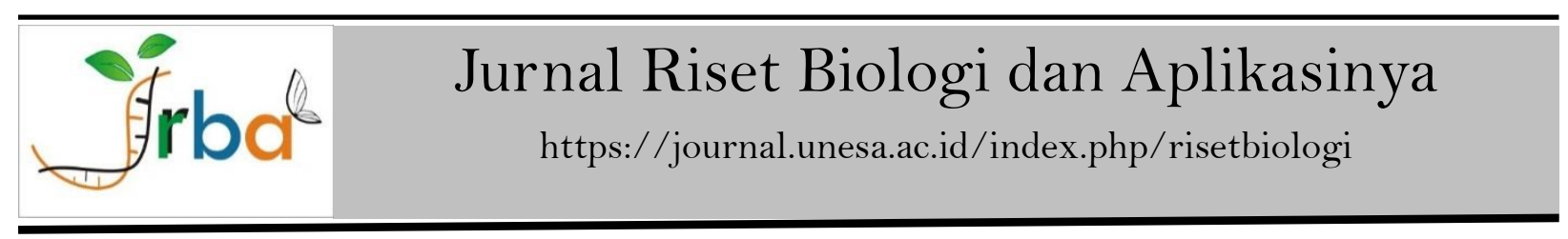

\title{
Aklimatisasi Tanaman Hasil Eksplorasi Tahura R. Soerjo dan Pulau Yamdena di Kebun Raya Purwodadi
}

\author{
The Acclimatization of Plants exploration Results from Tahura R. Soerjo and Yamdena Island \\ in Purwodadi Botanic Garden
}

\author{
Apriyono Rahadiantoro ${ }^{1}$ dan Nita Dwi Indahsari ${ }^{2}$ \\ 1*Purwodadi Botanic Garden, Research Center for Plant Conservation and Botanic Gardens, \\ Indonesian Institute of Sciences Indonesia (LIPI), Purwodadi-Pasuruan \\ ${ }^{2}$ Jurusan Biologi, Fakultas Sains dan Teknologi, Universitas Airlangga, Surabaya
}

\section{History Article}

Received : 29 Juli 2019

Approved : 9 Agustus 2019

Published : 30 September 2019

\section{Keywords:}

exsitu conservation; Tahura R.

Soerjo; Yamdena Island; acclimatization; Purwodadi Botanic

Garden; survival rates

\section{Kata Kunci}

Konservasi exsitu; Tahura R.

Soerjo; Pulau Yamdena;

aklimatisasi; Kebun Raya

Purwodadi; tingkat kelangsungan

hidup

\begin{abstract}
Abstrak
Kebun Raya Purwodadi sebagai lembaga konservasi exsitu yang mengoleksi berbagai jenis tumbuhan terutama dataran rendah kering kembali mengirimkan tim eksplorasi di beberapa kawasan hutan di Indonesia. Tanaman hasil eksplorasi tersebut sebelum menjadi tanaman koleksi membutuhkan proses adaptasi terhadap kondisi lingkungan baru yang dikenal dengan istilah aklimatisasi tanaman. Proses tersebut dapat berlangsung lama dan menjadi salah satu tahapan yang kritis dalam konservasi tumbuhan dikarenakan adanya tingkat kelangsungan hidup tanaman. Tujuan penelitian ini adalah untuk menentukan tingkat ketinggian hidup tanaman dari Tahura R. Soerjo dan Pulau Yamdena serta mempelajari faktor-faktor yang mempengaruhinya. Berdasarkan hasil penelitian diketahui bahwa tingkat kelangsungan hidup tanaman di kedua lokasi tersebut berbeda. Tanaman Tahura R. Soerjo memiliki tingkat kelangsungan hidup yang lebih tinggi dibandingkan Pulau Yamdena. Berdasarkan analisis, faktor-faktor yang mempengaruhi tingkat kelangsungan hidup tanaman pada kedua lokasi tersebut lebih dikarenakan oleh kondisi iklim mikro lokasi asal dibandingkan zona ketinggiannya, sedangkan untuk jenis material tanaman masih dibutuhkan penelitian lebih lanjut.
\end{abstract}

\begin{abstract}
Purwodadi Botanic Garden as an exsitu conservation area again explored plants in several forest areas in Indonesia. Plants that are explored to become a collection plant must go through a process of adaptation to new environment known as the acclimatization process. The process can take place in quite a long time and is one of the critical stages in plant conservation activities because it is related to the survival rate of plants. The purposes of this research were to determine the survival rates of plant from Tahura R. Soerjo, Yamdena Island and describe the factors influence it. Based on research it is known that the survival rates of plants in the two locations are different. Tahura R. Soerjo plant has a survival rate which is higher than Yamdena Island. Based on the analysis, the factors that affect the survival rate of plants at the two locations are caused by microclimate conditions than the altitude zone, while for the type of plant material, further research is needed.
\end{abstract}

How to cite: Rahardiantoro, A \& Indahsari, N.D. (2019). Aklimatisasi Tanaman Hasil Eksplorasi Tahura R. Soerjo dan Pulau Yamdena di Kebun Raya Purwodadi. Jurnal Riset Biologi dan Aplikasinya. 1 (2): 87-91. 


\section{PENDAHULUAN}

Kebun Raya Purwodadi merupakan kawasan konservasi eksitu yang mana kegiatan pelestarian tumbuhannya dilakukan di luar habitat asli. Jenisjenis tumbuhan kawasan dataran rendah kering menjadi ciri khas kebun raya tersebut (Lestarini dkk., 2012). Sebagai lembaga konservasi eksitu, Kebun Raya Purwodadi berperan penting dalam berbagai fungsi konservasi meliputi eksplorasi tumbuhan, pengelolaan koleksi tumbuhan, penelitian dan pengembangan konservasi tumbuhan dataran rendah kering. Dalam kaitannya dengan fungsi tersebut, Kebun Raya Purwodadi kembali mengirimkan tim eksplorasi tumbuhan di beberapa kawasan di Indonesia, salah satunya Taman Hutan Raya (Tahura) R. Soerjo di Lereng Gunung Arjuno, Jawa Timur dan Hutan Pulau Yamdena di Kepulauan Tanimbar, Maluku Tenggara Barat. untuk menjadi koleksi kebun, tanaman hasil eksplorasi tersebut harus melalui beberapa tahap yang cukup lama agar dapat beradaptasi pada lingkungan baru. Tahapan tersebut lebih dikenal dengan istilah proses aklimatisasi tanaman.

Dalam mendukung proses aklimatisasi, Kebun Raya Purwodadi membentuk subunit khusus yang dinamakan subunit bidang aklimatisasi. Acuan utama subunit tersebut adalah menyediakan bibit yang siap untuk ditanam kebun. Proses aklimatisasi bertujuan untuk membantu tanaman hasil eksplorasi agar dapat beradaptasi pada kondisi lingkungan yang baru, dalam hal ini ada area kebun (Trimanto, 2012). Dalam proses aklimatisasi perlu dilakukan monitoring secara berkala untuk mengetahui tingkat kelangsungan hidup tanaman hasil eksplorasi dan mempelajari faktor-faktor apa yang mempengaruhinya. Tujuan dari penelitian ini adalah mengetahui tingkat kelangsungan hidup tanaman dari Tahura R. Soerjo dan Pulau Yamdena serta mempelajari faktor-faktor yang mempengaruhinya.

\section{BAHAN DAN METODE}

Kegiatan aklimatisasi dan monitoring tanaman hasil eksplorasi dilakukan di area rumah kaca, subunit aklimatisasi, pengembangan dan kompos, Kebun Raya Purwodadi-LIPI. Proses monitoring dilakukan pada Desember 2018. Metode yang digunakan pada penelitian ini yaitu menggunakan teknik observasi untuk mengetahui tingkat kelangsungan hidup tanaman hasil eksplorasi serta wawancara dan studi literatur untuk mempelajari faktor-faktor apa saja yang mempengaruhnya. Alat yang digunakan dalam proses monitoring meliputi pengukur intensitas cahaya matahari (luxmeter), pengukur keasaman media ( $\mathrm{pH}$ meter tanah) pengukur suhu udara (thermometer), pengukur kelembaban udara (higrometer), kamera, label dan alat tulis. Parameter yang diamati meliputi jumlah tanaman asal, jumlah tanaman yang hidup pada saat monitoring, jenis material tanaman dan faktorfaktor lingkungan yang mempengaruhinya meliputi intensitas cahaya, suhu dan kelembaban udara. Tingkat kelangsungan hidup tanaman dihitung menggunakan rumus persentase tanaman yang hidup.

Persentase tanaman yang hidup (\%) = jumlah bibit yang hidup pada saat monitoring
jumlah bibit awal

\section{HASIL DAN PEMBAHASAN}

Proses aklimatisasi merupakan salah satu tahap kritis dalam kegiatan konservasi tumbuhan di Indonesia yang menentukan apakah suatu tanaman dapat beradaptasi dengan baik atau tidak terhadap lingkungan baru. Menurut Trimanto (2012), proses aklimatisasi di Kebun Raya Purwodadi secara umum dilakukan melalui proses penanaman material tanaman hasil eksplorasi pada media pasir dan pemberian sungkup selama beberapa bulan. Media pasir sering digunakan sebagai media tumbuh bibit hasil eksplorasi karena mempunyai berbagai keunggulan. Media pasir memiliki porositas yang tinggi sehingga membantu pertumbuhan akar dan memudahkan proses penggantian media sehingga tanaman tidak mengalami stress berlebih. Media pasir yang minim nutrisi atau unsur hara memiliki keuntungan yaitu mengurangi pertumbuhan tanaman gulma di sekitar material tanaman hasil eksplorasi. Hal tersebut telah sesuai yang disampaikan oleh Febrianto (2015) bahwa beberapa syarat media yang baik untuk aklimatisasi antara lain aerasi yang baik untuk memudahkan pertumbuhan akar dan tidak mudah ditumbuhi jamur. Untuk menyiasati rendahnya unsur hara maka material tanaman khususnya dari material bibit atau stek perlu ditambahkan zat penumbuh akar. Pemberian zat penumbuh akar bisa dilakukan dengan merendam bagian akar atau batang stek kedalam media penumbuh akar. Khusus material tanaman dari biji atau umbi tidak perlu diberikan zat penumbuh akar dikarena material tanaman tersebut memiliki cadangan makan sendiri untuk tumbuh dan berkembang. Kelebihan tersebut menjadikan media pasir sering digunakan sebagai media untuk proses perkecambahan biji. 
Proses penyungkupan material tanaman dilakukan secara bertahap yaitu diawali penyungkupan $100 \%$, lalu penyungkupan $50 \%$ hingga sungkup dibuka secara total. Proses penyungkupan tersebut bertujuan menjaga kelembaban udara iklim mikro bibit tanaman dan disesuaikan dengan keadaan kondisi lingkungan di sekitarnya. Setelah proses penyungkupan bertahap maka dilakukan pemindahan tanaman ke dalam media polybag di area pembibitan. Media polybag yang digunakan bervariasi komposisi bahannya. Untuk bibit pohon, komposisi sekam, katel, dan kompos adalah dengan perbandingan $1: 2: 1$ sedangkan tanaman herba dan paku terestrial $2: 1$ : 1 (Permatasari \& Rahadiantoro, 2015; Trimanto \& Rahadiantoro, 2017). Febrianto (2015) menyatakan bahwa beberapa syarat media yang baik adalah memiliki kemampuan menahan air yang tinggi dan aerasi yang baik. Katel atau tanah endapan sungai mempunyai sifat sebagai penahan air yang tinggi, sementara sekam dan kompos berfungsi agar pertukaran udara (aerasi) berlangsung dengan yang baik dan kebutuhan unsur hara atau nutrisi tanaman tercukupi. Selain itu perawatan bibit tanaman meliputi penyiraman, penyiangan dari tanaman gulma, dan penyemprotan hama perlu dilakukan secara rutin hingga tanaman siap ditanam di kebun.

Tingkat kelangsungan hidup tanaman hidup hasil eksplorasi Tahura R. Soerjo lebih tinggi jika dibandingkan Pulau Yamdena. Jenis material tanaman juga mempengaruhi tingkat kelangsungan hidup tanaman. Untuk tanaman hasil eksplorasi yang berasal dari Pulau Yamdena, jenis material biji merupakan salah satu penyebab penurunan nilai persentase tanaman yang hidup yaitu dari 47,8 \% menjadi $33 \%$ (Tabel 1). Jenis material tertentu terutama biji lebih sulit untuk ditentukan berapa jumah tanaman yang hidup karena sulit dibedakan biji yang dorman dan mati. Berapa jenis biji tanaman memiliki kulit yang keras dan masa dorman yang sangat lama. Selain dari jenis material tanaman, parameter lain yang bisa diamati adalah kondisi lingkungan atau habitat asal tanaman meliputi ketinggian lokasi (topografi), kerapatan vegetasi pohon penyusun hutan dan kondisi lingkungan (iklim mikro) yang terbentuk di dalamnya (Tabel 2). Lokasi Tahura R. Soerjo tergolong kawasan hutan pegunungan bawah (submontana) dengan ketinggian sekitar 1.000$1.400 \mathrm{~m} \mathrm{dpl}$ (meter di atas permukaan laut) dengan kondisi vegetasi pohon cenderung jarang dan kondisi lingkungan yang terbuka serta relatif kering. Sementara hutan Pulau Yamdena merupakan kawasan hutan dataran rendah dengan ketinggian sekitar 50-300 $\mathrm{m}$ dpl dengan kondisi vegetasi pohon rapat dan kondisi lingkungan sekitar yang cenderung ternaung dan memiliki kelembaban udara yang relatif tinggi (Irawanto dkk., 2018). Selain itu, berdasarkan pengamatan di hutan, kondisi serasah tanah juga sangat berbeda di kedua lokasi tersebut.

Hutan Pulau Yamdena memiliki serasah yang tebal dan banyak dijumpai anakan pohon sedangkan Tahura R. Soerjo lebih tipis sedikit dijumpai anakan pohon. Berdasarkan pengamatan kondisi lingkungan diketahui bahwa Tahura R. Soerjo walaupun berada pada zona ketinggian submontana. Dalam hubungannya dengan kesesuaian habitat bagi tanaman maka hutan R. Soerjo lebih sesuai dibandingkan hutan Yamdena walaupun segi ketinggian lokasi berbeda. Berdasarkan pengamat lebih mendalam dapat diketahui bahwa kondisi lingkungan atau iklim mikro yang terbentuk di dalam hutan mempunyai pengaruh yang kuat terhadap karakter vegetasi tumbuhan, terutama kondisi kelembaban udara atau bagaimana kondisi serasah lantai hutan di dalamnya maka masingmasing jenis tanaman memiliki relung ekologis yang spesifik.

Persentase tanaman yang hidup Tahura R. Soerjo berdasarkan jenis material tanamannya bervariasi. Persentase tanaman yang hidup tertinggi secara berurutan disumbangkan oleh jenis material umbi, biji dan anakan dengan nilai masingmasing $100 \%$, $88 \%$ dan $77 \%$ (Gambar 1). Nilai persentase tanaman yang hidup terendah adalah dimiliki jenis material stek sebesar $53 \%$. Permatasari \& Rahadiantoro (2015) menyatakan bahwa nilai persentase tanaman hidup Tahura R. Soerjo relatif lebih tinggi dibandingkan Pulau Sempu (71,48 \%). Berdasarkan analisis lebih mendalam, presentase kematian tanaman terbesar adalah ketika proses pemindahan material tanaman dari bak pasir ke lokasi pembesaran bibit. Hal tersebut bisa terjadi karena tanaman mengalami stress atau kondisi lingkungan sangat berbeda dengan habitat asli. Persentase hidup jenis material yang rendah juga bisa disebabkan oleh faktor lain. Jenis material umbi dan biji memiliki persentase hidup tanaman yang tinggi dikarenakan material umbi dan biji tersebut memiliki cadangan makanan yang cukup untuk proses pertumbuhan tanaman. Jenis material tanaman stek terkenal memiliki tingkat kematian yang tinggi. Kebanyakan material tanaman jenis stek mengalami mati akar atau kering batang. 
Tabel 1. Tingkat kelangsungan hidup hasil eksplorasi Kebun Raya Purwodadi

\begin{tabular}{ccc}
\hline Lokasi & $\begin{array}{r}\text { Jenis material tanaman (anakan, stek, umbi atau biji) } \\
\text { semua }\end{array}$ & $\begin{array}{c}\text { tanpa material biji } \\
\text { Tahura R. Soerjo }\end{array}$ \\
Pulau Yamdena & $73,8 \%$ & $71,8 \%$ \\
\hline
\end{tabular}

Tabel 2. Kondisi lingkungan di kedua lokasi eksplorasi dan Kebun Raya Purwodadi

\begin{tabular}{|c|c|c|c|c|c|}
\hline \multirow[b]{2}{*}{ Lokasi } & \multirow[b]{2}{*}{$\begin{array}{c}\text { Zona } \\
\text { ketinggian } \\
\text { ( m dpl) }\end{array}$} & \multicolumn{4}{|c|}{ Kondisi iklim mikro } \\
\hline & & $\begin{array}{c}\text { Vegetasi pohon } \\
\text { dan ketebalan } \\
\text { serasah }\end{array}$ & $\begin{array}{l}\text { Kelembaban } \\
\text { udara (\%) }\end{array}$ & $\begin{array}{c}\text { Intensitas cahaya } \\
(\mathrm{lux})\end{array}$ & $\begin{array}{l}\text { Suhu udara } \\
\qquad\left({ }^{\circ} \mathrm{C}\right)\end{array}$ \\
\hline $\begin{array}{l}\text { Tahura R. } \\
\text { Soerjo }\end{array}$ & $\begin{array}{l}\text { submontana } \\
(1000-1400)\end{array}$ & $\begin{array}{l}\text { jarang, lapisan } \\
\text { humus tipis }\end{array}$ & Kering $(60-70)$ & $\begin{array}{l}1.000-40.000 \\
\text { (sedang) }\end{array}$ & 23-25 \\
\hline $\begin{array}{l}\text { Hutan Pulau } \\
\text { Yamdena }\end{array}$ & $\begin{array}{l}\text { dataran } \\
\text { rendah } \\
(50-300)\end{array}$ & $\begin{array}{l}\text { rapat, lapisan } \\
\text { humus tebal }\end{array}$ & lembab (78-82) & $160-413$ (rendah) & 29-32 \\
\hline $\begin{array}{l}\text { Kebun Raya } \\
\text { Purwodadi }\end{array}$ & $\begin{array}{l}\text { dataran } \\
\text { rendah } \\
(300)\end{array}$ & $\begin{array}{l}\text { jarang, lapisan } \\
\text { humus tipis }\end{array}$ & kering (65-73) & $\begin{array}{l}2.000-100.000 \\
\text { (tinggi) }\end{array}$ & $30-34$ \\
\hline
\end{tabular}

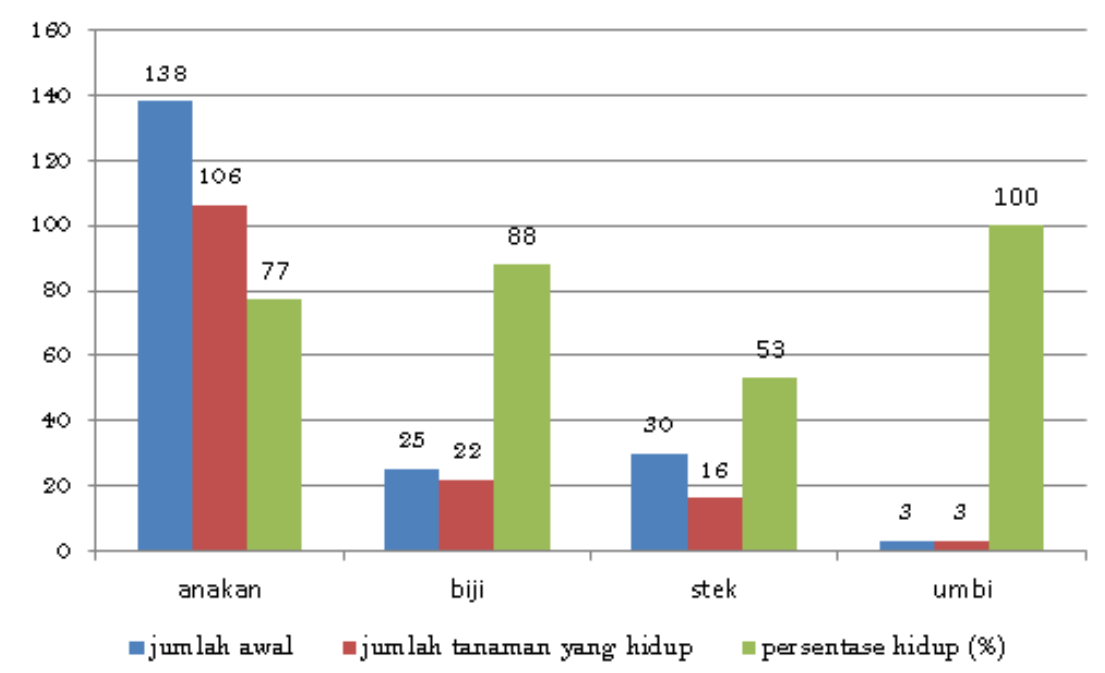

Gambar 1. Data tanaman Tahura R. Soerjo yang hidup berdasarkan jenis material tanamannya

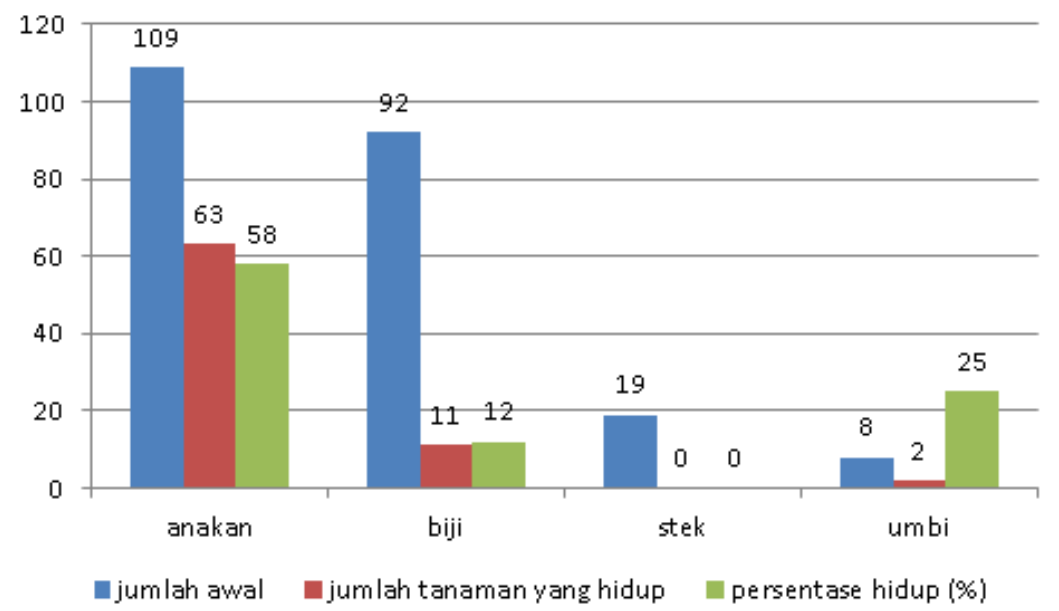

Gambar 2. Data tanaman Pulau Yamdena yang hidup berdasarkan jenis material tanamannya 
Trimanto (2012) menyatakan bahwa salah satu faktor yang penting dalam aklimatisasi adalah pertumbuhan akar. Penentuan tanaman untuk stek yang kurang baik berakibat pada ketidakmampuan tanaman untuk menumbuhkan akar. Hal tersebut merupakan penyebab tanaman stek kering dan mati.

Persentase tanaman yang hidup dari Pulau Yamdena cenderung rendah. Persentase tanaman hidup jenis material anakan hanya $58 \%$ atau separuh bibit tanaman yang masih bertahan hidup, kemudian dilanjutkan umbi, biji dan stek masingmasing $25 \%, 12 \%$ dan o (Gambar 2). Untuk jenis material stek, tidak ditemukan tanaman yang hidup. Hal tersebut dapat mengindikasikan adanya ketidaksesuai habitat yang sangat mencolok antara Kebun Raya Purwodadi dan Pulau Yamdena, salah satunya terutama adalah tingkat kelembaban udara. Kondisi kelembaban udara yang lebih kering dibandingkan dengan habitat asal mengakibatkan batang (stek) tanaman mengalami stress berlebih sehingga proses pembentukan akar terganggu lalu tanaman jadi kering dan mati. Persentase hidup jenis material yang rendah juga bisa disebabkan oleh faktor lain. Jenis material biji relatif lebih sulit untuk apakah biji tersebut berada dalam fase dorman atau mati sehingga biji yang tidak berkecambah dianggap tidak tumbuh saat dilakukan monitoring.

\section{SIMPULAN}

Berdasarkan hasil penelitian diketahui bahwa tingkat kelangsungan hidup tanaman di kedua lokasi tersebut berbeda. Tanaman Tahura R. Soerjo memiliki tingkat kelangsungan hidup yang lebih tinggi dibandingkan Pulau Yamdena. Berdasarkan analisis, faktor-faktor yang mempengaruhi tingkat kelangsungan hidup tanaman pada kedua lokasi tersebut lebih dikarenakan oleh kondisi iklim mikro habitat asal dibandingkan zona ketinggiannya. Tahura R. Soerjo secara keseluruhan memiliki kondisi iklim mikro yang lebih mirip Kebun Raya Purwodadi dibandingkan Pulau Yamdena. Sedangkan jenis material tanaman secara keseluruhan masih dibutuhkan penelitian lebih mendalam apakah berpengaruh terhadap kelangsungan hidup tanaman. Hasil penelitian tersebut diharapkan dapat digunakan sebagai dasar rekomendasi perbaikan teknik aklimatisasi tanaman yang dilakukan di Kebun Raya.

\section{DAFTAR PUSTAKA}

Irawanto R, Rahadiantoro A, Mudiana D, Suhadinoto, Sumaji, Rumadi, Huda A, Sampu, Saniman, Purnomo D, Gizano R. (2018). Taman Hutan R. Soerjo sebagai Ikon Ekosistem Hutan Pegunungan tersisa di Pulau Jawa. Program Kerjasama Konservasi Tumbuhan BKT Kebun Raya Purwodadi-PT Gudang Garam Tbk.

Febrianto, R. S \& Syamsuardi. (2015). Aklimatisasi Planlet Kantong Semar (Nepenthes gracilis Korth.) pada berbagai Campuran Media Tanam Tanah Ultisol. Jurnal Biologi Universitas Andalas 4 (2): 96-101. Doi: https://doi.org/10.25077/jbioua.4.2.\%25p.20 15.

Permatasari I \& Rahadiantoro A. (2015). Tahap Aklimatisasi dan Monitoring Tanaman Hasil Eksplorasi Pulau Sempu: Blok Waru-Waru di Kebun Raya Purwodadi. Prosiding Seminar Nasional Biologi / IPA dan Pembelajarannya. Universitas Negeri Malang. Diakses dari https://docplayer.info/67651129-Tahapaklimatisasi-dan-monitoring-tanaman-hasileksplorasi-pulauu-sempu-blok-waru-waru-dipurwodadi.html.

Trimanto \& Rahadiantoro A. (2017). Acclimatization of plant collection from Moyo Island Forest, West Nusa Tenggara, Indonesia at Purwodadi Botanic Garden. Trop Drylands, 1: 43-49. $\quad \mathrm{D}_{92}$ https://doi.org/10.13057/tropdrylands/tO Iu 107.

Trimanto T. (2012). Aklimatisasi tumbuhan hasil eksplorasi dan perbanyakan tanaman unit seleksi dan pembibitan kebun raya purwodadi. Prosiding Seminar Nasional $X$ Pendidikan Biologi. FKIP UNS. Diakses dari https://jurnal.fkip.uns.ac.id/index.php/prosb io/article/view/3194.

Lestarini W, Matrani, Sulasmi, Trimanto, Fauziah, Fiqa AP. (2012). An alphabetical list of plant species cultived in the Purwodadi Botanic Garden. Purwodadi Botanic Garden, Pasuruan. Diakses dari http://www.krpurwodadi.lipi.go.id/unduhan /katalog_rumahkaca_2016_KRP.pdf. 